\title{
AUTHOR'S PREFACE.
}

My design in the present undertaking is to compose a comprehensive picture of the department of knowledge in which, during several decades past, I have been at pains to increase the material and to sift the problems. The work, which summarizes the labours of a lifetime, will be complete in three volumes, and will, it is hoped, be accessible to wide circles of cultivated readers. The point of view from which I have written is not that of any onesided and exclusive school. I endeavour to do equal justice to the different tendencies of ancient thought, every one of which has contributed its part to the complete structure of modern intellectual civilization, to consider them all impartially, and to judge them fairly. The historical relief in which the narrative is set will not be unduly contracted, and its subjective features will be confined to emphasizing what is essential as sharply as possible, and to sundering as thoroughly as possible what is enduring and significant from what is indifferent and transient. Portions of the story of religion, of literature, and of the special sciences, indispensable to an understanding of the speculative movement, its causes and effects, will be incorporated in the work. The boundaries dividing these provinces appear to me in all cases to be floating. The ideal I have in view could only completely be realized in an exhaustive universal history of the mind of antiquity. When so monumental an undertaking has been successfully 
effected I shall be the first to admit that the present far more modest attempt is superseded and antiquated.

The second volume and the third or concluding volume will comprise the remaining six books, entitled respectively, (4) "Socrates and the Socratics," (5) "Plato and the Academy," (6) "Aristotle and his Successors," (7) "The Older Stoa," (8) "The Garden of Epicurus," and (9) "Mystics, Sceptics, and Syncretists." In order not unduly to increase the compass of the work, the evidence of authorities has had to be reduced to the smallest dimensions, and, with regard to references to the later literature of the subject, economy has had to be practised in all cases excepting those where my own exposition may claim the greatest originality and those, again, where it can claim the least. In the latter instance the obligation has arisen of acknowledging my close dependence on predecessors, and, in the former, of advancing grounds for my radical divergence from traditional views.

Finally, I may be permitted, not to palliate, but to apologize for, the shortcomings of my work in the phrase employed in a letter of Gustave Flaubert to Georges Sand : "Je fais tout ce que je peux continuellement pour élargir ma cervelle, et je travaille dans la sincérité de mon cœur; le reste ne dépend pas de moi."

TH. GOMPERZ.

VIENNA. 